\title{
CONTROL SOCIAL Y CASTIGO: percepción del castigo en funcionarios policiales venezolanos
}

\author{
Yoana Monsalve Briceño*
}

\begin{abstract}
O artigo aborda as questões do significado policial do castigo e as justificativas morais de sua aplicação, utilizando dados provenientes de 14 entrevistas com funcionários de dois corpos policiais da área de Caracas, Venezuela. Se bem que, à primeira vista, o exercício do poder de castigar seja percebido pelos policiais como competência dos juízes penais, uma leitura mais detalhada indica que eles percebem, entre os cidadãos, uma demanda para atuar como executores diretos do castigo. Com isso, manifestam-se formas de organização e justificação dos castigos ilegais, assumindo esses policiais uma delegação ou um consentimento implícito por parte de outros operadores do sistema de justiça. Maniffesta-se também a emergência de uma "clientela" do castigo, formada por pessoas moralmente desvalorizadas e com escasso poder de reivindicação social, ainda que ambas as dimensões guardem certa autonomia. Conclui-se com proposições para ampliar o âmbito da investigação e para analisar a extensão e consistência das percepções de ineficiência do sistema formal de justiça penal e sua influência no desenvolvimento do poder de castigo direto por parte da polícia.

PALAVRAS-CHAVE: castigo, polícia, justiça penal, controle informal, moralidade, Venezuela
\end{abstract}

\section{CONTROL SOCIAL Y CASTIGO}

La conducta humana se encuentra sometida al control social, entendiendo por este los mecanismos que operan desde la definición hasta la supresión de comportamientos calificados como delictivos o desviados. La activación de agencias formales e informales con relación a conductas desaprobadas y la respuesta sancionatoria (Gabaldón, 1987, p.11) implica una forma de castigo, en la medida en que llevan aparejado algún tipo de privación. Grabosky (1984, p.170) sostiene que en el proceso de socialización se fijan la valoración de las conductas y los tipos de respuesta para graduar el castigo, lo cual sugiere alguna forma de estandarización de las conductas censurables y de los castigos en los procesos de control social.

\footnotetext{
*Advogada. Mestre em Planejamento do Desenvolvimento, Política Social pela Universidade Central de Venezuela. Professora do Departamento de Controle Social, Universidade de Los Andes, Escola de Criminologia. Av. Las Américas Núcleo La Líria. Edif. Postgrado. Venezuela. yoanamob@ula.ve
}

La interacción social es premisa fundamental para ayudar a comprender el significado del castigo. Cuando se trata de instancias informales, existe mayor variabilidad de las definiciones y las respuestas en cuanto a la conducta inaceptable. En las familias, por ejemplo, hay distintas maneras de definir la permisividad de la diversión fuera de la casa, y de responder ante el desacato, por parte de los hijos, en cuanto a la hora de reingreso. Esta variabilidad es una de las propiedades de las agencias informales de control social. Por el contrario, uno de los rasgos de las instancias formales del control social es contar con tipologías de comportamiento preestablecidas y mantener reacciones estandarizadas frente a la desviación, usualmente previstas en normas de procedimiento.

Las definiciones y reacciones estandarizadas de las agencias formales de control social deberían hacer más previsibles las opciones de control social, tanto para los operadores del sistema de justicia penal como para los ciudadanos. En el Estado moderno, el principio de legalidad exige normas formales para definir tipos 
delictivos y penas dentro de parámetros relativamente rígidos. Las normas definen delitos y modalidades admisibles de sanción. El castigo, por consiguiente, debería estar vinculado a normas y reglas. Algunos autores, aún dentro de una perspectiva sociológica, vinculan el castigo legal a la respuesta frente a transgresiones de normas preestablecidas. Así, Grabosky (1984, p.163) dice que castigo es la imposición deliberada de dolor o privación por parte de una autoridad en respuesta a la trasgresión a una norma. Garland (1999, p.330) sostiene que el castigo es un procedimiento legal que sanciona y condena a los trasgresores del derecho penal, de acuerdo con categorías y procedimientos legales específicos. Del Olmo (1990, p.40) considera el castigo legal como la última etapa del control social y la manifestación más clara de la ideología dominante del Estado. Mientras Grabosky se refiere al castigo en forma amplia, Garland y Del Olmo enfatizan que el procedimiento se activa ante la trasgresión de normas jurídicas, y como expresión de un poder legalizado por el Estado.

La respuesta que se manifiesta en represión autorizada, de acuerdo con procedimientos específicos del Estado, hace referencia a titulares específicos de dicho poder, lo cual se encuentra reglamentado. La actividad de castigar es selectiva, por cuanto las agencias de control social formal no se activan con la misma prestancia frente a cualquier infracción, ni la respuesta es equivalente para todas las situaciones normativamente equivalentes (Gabaldón, 1987, p.122 ss.; Zaffaroni, 1989, p.20 ss.).En todo caso, dentro del sistema moderno de la legalidad, la potestad de castigo corresponde al poder jurisdiccional, con base al reconocimiento de los principios de la división de poderes y del aseguramiento de las garantías individuales.

Ahora bien, la policía es una agencia de control social. Si ello es así, ¿tiene la policía poder para castigar?; en el caso de que lo tuviere, ¿cuáles son sus límites y las variables que predicen su ejercicio?; y si se ejerce, ¿cuáles son las razones y justificaciones aducidas para su aplicación? Estos son los temas de la presente investigación.

\section{POLICÍA Y USO DE LA FUERZA FÍSICA}

El Estado ha conferido a la policía determinadas facultades o poderes. Entre ellos, el uso de fuerza y manejo de instrumentos, como el bastón de mando y las armas de fuego. Gabaldón (1987, p.11) define esta agencia como una institución de carácter estatal, dotada de poder coactivo inmediato, encargada primordialmente de individualizar, detectar al autor, restringir y (o) prevenir conductas consideradas como jurídicamente inaceptables.

Con frecuencia, surgen cuestionamientos sobre los abusos o excesos en el uso de fuerza frente a la ciudadanía. Los cuestionamientos suponen que, bien se ha utilizado la fuerza fuera de un supuesto legalmente autorizado, bien se ha excedido de la cantidad autorizada en su aplicación (Provea, 2003). Muchos de los supuestos denunciados implican la utilización de la fuerza como castigo, cuando se supone que el uso de la fuerza es meramente instrumental para evitar la comisión de un delito y (o) el sometimiento del ciudadano.

Birkbeck y Gabaldón (2003, p.130-131) sostienen que las variables típicamente asociadas a la justificación de la fuerza empleada por la policía son el comportamiento del ciudadano, el tipo de la fuerza empleada y el objetivo que persigue el funcionario con su utilización. Ellos sugieren que comportamiento ciudadano y objetivo perseguido con la utilización de la fuerza podrían "estirarse" hacia atrás o hacia adelante, para cubrir supuestos que rebasan la conducta manifiesta en el momento del encuentro con la policía. Este estiramiento, cuando se trata del comportamiento ciudadano, podría incluir un juicio moral sobre cosas buenas o malas que el individuo haya realizado con anterioridad a la situación en la cual se produjo el contacto con la policía. Si ello es así, es factible suponer que la 
utilización de la fuerza por parte de la policía comprenda una dimensión moral, a su vez vinculada con la idea de castigo. La literatura sobre la policía frecuentemente enfatiza el hecho de que los policías realizan juicios sobre la culpabilidad de los infractores, que tienen contenido moral, y frente a los cuales pueden decidir la aplicación directa de alguna forma de castigo (Manning, 2003, p.21-23; Skolnick, 1975, p.215; Gabaldón; Birkbeck; Bettiol, 1990, p.135-154).

En un trabajo reciente, Black (2004, p.152153) ha sugerido que la moralidad se hace más rígida, dura e intolerante por parte de supraordinados hacia subordinados. En el control estatal, que es formalista y distante, se darían las condiciones óptimas para la rigidez y endurecimiento del juicio moral; sin embargo, también hay espacios para juicios morales más paternalistas y blandos, pero no por ello menos cargados de censura, cuando hay más intimidad, siempre que persistan las relaciones de subordinación. La policía es una agencia estatal y, en este sentido formal, que de acuerdo a los sujetos con los cuales interactúa, puede tener mayor o menor distancia, pero, en todo caso, estaría propensa a desarrollar y a aplicar juicios morales, que pueden fundamentar y justificar los castigos impuestos sobre el terreno. Por ello, las implicaciones morales del castigo son relevantes en el análisis y explicación del comportamiento policial.

Si la policía puede realizar juicios morales sobre el comportamiento de los ciudadanos, y si desarrolla perspectivas de desconfianza sobre el sistema formal de justicia penal, en particular hacia la rama jurisdiccional, como entidad a la que se reserva la imposición del castigo legal, tenemos las condiciones para explicar la aplicación directa de castigos mediante el uso de la fuerza física. Hay indicaciones, en la literatura norteamericana, sobre la desconfianza policial en el sistema formal de justicia, en casos vinculados a lo que se ha denominado el cinismo policial (Skolnick 1975, p.162; Walker,1992, p.6162). En América Latina, la literatura destaca, frecuentemente, la alienación de la policía frente al sistema legal, bien sea por desconfianza y marginación (Huggins; Haritos Fatouros, 1996, p.323-325; Santos, 1992, p.86), bien sea por presiones políticas y sociales para el control delictivo (Cano, 2001, p.227-234; Stanley, 2001, p.239).

En el caso venezolano, en particular, la investigación disponible sugiere que existen actitudes de desconfianza entre el público frente al sistema judicial, que justifican la aplicación de castigos extremos por parte de la policía (Briceño León, 2002, p.185-189), así como la inexistencia de mecanismos de rendición de cuentas que controlen los relatos y las razones empleadas en la utilización de formas extremas de fuerza física (Birkbeck; Gabaldón, 2003, p.128-129). A ello se añade que, con la reforma procesal de 1998, a la policía le fueron restringidas facultades de detención preventiva que operaban como castigos funcionales y sustitutivos del castigo judicial. El nuevo sistema procesal, en la medida en que resulta más exigente sobre las evidencias y pruebas para el dictado de medidas de aseguramiento personal y sentencias condenatorias, podría ser visto como complaciente e ineficaz. Es posible suponer, entonces, que la policía llegue a definir como materia de su competencia la aplicación directa de castigos, mediante el uso de la fuerza física, en una manera que rebasa su utilización puramente instrumental para evitar la comisión de un delito o lograr la aprensión del delincuente.

\section{DOS PROPOSICIONES SOBRE EL PODER DE CASTIGO DE LA POLICÍA}

Las dos proposiciones que orientan la discusión que a continuación planteo son las siguientes:

1. La policía tiene una visión del castigo que concurre con la potestad jurisdiccional de sancionar. Si bien una lectura estrictamente legalista de las potestades policiales no incluyen el castigo como retribución por la conducta inapropiada, la literatura sobre la policía sugiere 
que ella no renuncia completamente a la facultad de castigar, si bien su reconocimiento no es explícito. A pesar de que los cuerpos policiales se rigen por directrices jerárquicas formales y aparentemente estrictas en cuanto al control de sus actividades, el trabajo policial genera prácticas compatibles con operaciones sin el apoyo de la ley, de las cuales es consciente el funcionario policial, quien utiliza el sistema de justicia penal para protegerse frente a reclamos ante eventuales excesos. Esto contribuye a sustraer de la discusión pública el tema de las faltas del policía (Manning, 1997, p.124). Por otro lado, la práctica policial ha sido vinculada a excesos provocados por los funcionarios, tales como torturas, maltrato físico, persecuciones y hasta la muerte de ciudadanos, que muchas veces pretenden ser justificadas bajo las figuras de estado de necesidad y legítima defensa (Santos, 1992, p.78, 80). Según Del Olmo (1990, p.55), la actividad de castigar ha sido asumida por la policía venezolana a través de prácticas que implican desapariciones, maltratos físicos y muertes de ciudadanos. Estas prácticas tenderían a ser justificadas, particularmente cuando se producen como consecuencia de excesos en operativos policiales, a través de la noción de orden público, aunque dichos castigos carezcan de autorización expresa y contraríen normas legales. Por consiguiente, no es sorprendente que la policía aplique castigos a los ciudadanos en el momento de la interacción con ocasión de la detección de delitos o faltas.

2. La policía realiza juicios morales sobre las conductas de los ciudadanos que pueden servir de base para la aplicación y (o) justificación de castigos directos. Aunque la consistencia y generalidad de los juicios morales de la policía sean un tema debatible, se ha observado que el trabajo policial genera contactos que llevan a los funcionarios a considerar, muchas veces, a las personas como inmorales o hipócritas (Manning, 1997, p.166), y que la criminalidad se encuentra asociada al incumplimiento de reglas morales y a la noción de reproche (Birkbeck; Gabaldón,
2001, p.99). Por otra parte, se ha sostenido (Scott; Lyman, 1989, p.117) que justificar un acto es afirmar su valor positivo frente a la pretensión contraria, y que una justificación radica, en sentido general, en el reconocimiento de que si bien el acto en cuestión sea generalmente inadmisible, bajo determinadas condiciones se encuentra permitido o puede resultar necesario. Si ello es así, la aplicación del castigo por parte de la policía, en la medida en que resulta un acto no estrictamente reglamentario, puede recurrir al juicio moral devaluativo del infractor para ser justificado o defendido. Ello, independientemente de que el acto mismo de castigar suponga una evaluación moral negativa del acto o del sujeto que lo realiza. Por estas razones, son de esperar manifestaciones policiales de devaluación moral sobre los sujetos a quienes se les aplica el castigo.

\section{METODOLOGÍA}

Esta investigación es una vertiente de un proyecto sobre el uso de fuerza policial que comenzó en 2001, con la participación de varios países (Gabaldón; Birkbeck, 2003, p.125 ss.). El objetivo fundamental tiene que ver con la identificación de justificaciones para el uso de fuerza física entre efectivos policiales. La metodología aplicada en cada uno de los países participantes en la investigación es el análisis, mediante grupos focales de discusión con funcionarios policiales, en torno a un escenario común para todos los países, de las opciones de intervención y su justificación en relación con un encuentro entre la policía y presuntos delincuentes. Allí se detalla una situación que progresa desde un encuentro inicial con sospechosos en un automóvil, presuntamente consumiendo drogas, hasta una fuga y disparos de los sospechosos hacia la policía. El objetivo radica en evaluar la utilización progresiva de la fuerza por parte de funcionarios policiales y las razones para su empleo, en un contexto de comparación internacional e intercultural. 
En el caso de Venezuela, se escogió el Distrito Capital, por representar la mayor concentración urbana y de funcionarios policiales uniformados del país. Fueron seleccionados dos cuerpos policiales municipales que denominaremos Polioriente y Polioccidente. El primero de ellos fue creado en 1993 y servía a una población de 72.789 habitantes, mientras que el segundo fue creado en 1995 y servía a una población de 1.974.323 habitantes, según cifras de OCEI para1996 (Márquez; Castillo,1996, p.168).

La base de datos de la presente discusión está dada por 14 entrevistas entre aproximadamente el $50 \%$ de los funcionarios participantes en los 4 grupos focales de discusión en torno al escenario progresivo del encuentro entre la policía y los ciudadanos sospechosos. Fueron seleccionados para las entrevistas aquellos funcionarios que mayor cantidad de comentarios realizaron, por considerarse más productivos para profundizar sobre las percepciones en cuanto al uso de la fuerza física y su posible significado como castigo. Las entrevistas fueron semi estructuradas, partiendo de percepciones iniciales sobre lo que se entiende en general por castigo, continuando con una elaboración en torno a la función policial y la descripción de episodios o casos en los cuales hubiesen participado los funcionarios entrevistados, como actores, testigos presenciales o referenciales, y que tuviesen que ver con la aplicación de medidas de fuerza o castigos a sospechosos o infractores. Los grupos focales fueron realizados entre el 27 y 31 de Octubre de 2003 y las entrevistas se realizaron entre el 16 de febrero y el 19 de Marzo de 2004.

Las entrevistas fueron realizadas en ambientes externos a las sedes de las policías en un 95\% de los casos. Una vez comenzada la conversación, los entrevistados mostraron interés por el tema a tratar, de manera que el tiempo más corto de entrevistas fue de 1 hora y 10 minutos, el más largo de 3 horas con 50 minutos. El tiempo total de entrevistas fue de 30 horas con 40 minutos.

$\mathrm{Al}$ inicio de las entrevistas, se garantizó la reserva en cuanto a la identidad, con la finalidad de asegurar confidencialidad, espontaneidad y confiabilidad de la información. Además se comentó que los resultados son solamente de interés académico y su publicación se haría a través de informes técnicos, artículos, o monografías en publicaciones especializadas.

Aunque se trabajó con dos cuerpos policiales del área metropolitana de Caracas, es importante aclarar que este proyecto de investigación no pretende evaluar, en ningún sentido, el desempeño o competencia de los cuerpos policiales participantes. Se trata más bien de una aproximación a la policía con pretensiones de generalizar, en lo posible, sobre su desempeño en materia de seguridad y control. Los resultados pueden contribuir, además, a implementar programas de entrenamiento, formación y perfeccionamiento en esta materia.

\section{RESULTADOS}

En cuanto al análisis de los datos, de acuerdo con las preguntas que orientan la investigación, se procedió a clasificar los contenidos en dos categorías que se vinculan a las dos proposiciones fundamentales. La primera tiene que ver con la apreciación que tienen funcionarios policiales sobre el castigo, y la segunda con los juicios morales que hacen los funcionarios policiales cuando se trata de desplegar las actividades tendientes a castigar. La discusión que se presenta a continuación se desarrolla en torno a estas dos proposiciones, utilizando extractos de las entrevistas realizadas para apoyar la interpretación.

\section{Visión policial del castigo}

Castigo, de acuerdo con la primera impresión de nuestros entrevistados, no es un término empleado dentro de la institución policial para controlar a la población civil. Es empleado 
ante el desacato de algunos funcionarios hacia sus superiores. Un funcionario dijo que lo emplea en su casa, ante sus hijos, pero nunca en la calle, en su trabajo como policía. De acuerdo con el análisis de las entrevistas realizadas, el castigo fue asociado a sanción, represión y coacción. También a maltrato, exceso policial, brutalidad, privación y resultado final del proceso penal, lo que sugiere un significado no uniforme, que incluye tanto consecuencias legales (sanción y culminación del proceso) como extralegales (maltrato, exceso y brutalidad). No hay duda, sin embargo, de su connotación como una reacción a alguna conducta inapropiada que no debe dejarse pasar por alto. Comentarios ilustran la conexión del mal justificado que implica el castigo con el mal inicial que lo provoca:

... castigo es una acción negativa, pero es justa siempre y cuando la conducta de la persona que se castiga haya sido mala, o porque hizo algo malo. (Entrevista 11)

...castigo [...] es lo que la persona no ve bien, mientras los funcionarios policiales verifican la información, radean. En esos momentos, las personas están bajo disposición del cuerpo policial y eso significa para nosotros que estamos castigando a alguien. (Entrevista 1)

...castigo es igual a amonestar o sancionar por una falta que se haya cometido [...] la amonestación puede ser verbal o por escrito, la privación de libertad en el argot policial es una especie de castigo, para que no lo vuelva a cometer. El castigo es persona recapacite. (Entrevista 8)

... castigo es acción o la pena que tiene una persona por haber cometido un hecho punible, por ser partícipe de un hecho punible y haber tenido participación en él. (Entrevista 2)

...castigo es como una sanción. Como era antes, o sea a los golpes, más que todo lo enfoco con los golpes [...] por ejemplo antes se colgaba a la gente. [...] nosotros tratamos de acogernos a la Ordenanza Municipal, pero se trata de castigar a la gente con golpes, pero con menos descaro... (Entrevista 5)

Se percibió, en el análisis de las entrevistas, que los policías definen el castigo como consecuencia directa que deriva de la discreción policial, al aplicarse una respuesta rápida en el terreno y ante cada situación. El castigo manifiesta una vinculación con la cotidianidad del oficio y refleja matices que van desde hacer perder tiempo al ciudadano, aprehenderlo, hasta el maltrato físico.

El total de entrevistados estuvo de acuerdo con que la actividad de castigar no corresponde "legalmente" al cuerpo de policía, aunque muchos de ellos admiten que hay una expectativa ciudadana frente a la aplicación del castigo policial bajo ciertos supuestos. Así lo ilustran los siguientes comentarios:

... los ciudadanos no consideran al funcionario policial como mediador, sino como una persona que tiene en sus funciones castigar. (Entrevista 11)

... no se debe, pero se aplica todos los días, todo el tiempo. (Entrevista 10)

... castigar no corresponde [...] pero castigar corresponde a las divisiones de inteligencia de toda policía... (Entrevista 8)

... no corresponde actualmente, antes del Código Orgánico Procesal Penal (1998), sí. (Entrevista 10)

Esta tensión entre la reserva "legal" para los jueces en el poder de castigar y lo que se percibe como una expectativa ciudadana hacia el castigo policial determina la "organización" de formas y procedimientos policiales que permitan instrumentar los castigos y que, en casos en que resulten reñidos con la legalidad formal, aseguren la eficacia de la función y la preservación frente a posibles investigaciones y reclamos:

... nosotros, los policías somos el brazo ejecutor de la ley, no el apoyo. Recabar la mayor cantidad de pruebas es para los funcionarios policiales un propósito claro. Con ellas se va a presentar el caso a la fiscalía [...] con ellas se prepara el regalito para que al juez no le quede dudas y castiguemos [...] como somos un equipo de trabajo, vamos a castigar, yo ayudo para que el juez decida que son culpables. (Entrevista 2)

De este comentario se desprende que el entrevistado percibe como útil la cooperación con entidades relativamente ajenas, como son la fiscalía y el tribunal, dado que las entrevistas refieren que la actividad policial se limita a redactar el acta policial. Queda a discreción del funcionario llamar al fiscal o no, según la gravedad de la situación, de acuerdo a varios 
comentarios, aunque legalmente no exista tal discrecionalidad y deba reportarse cualquier investigación de carácter penal. En otros casos, el juez puede solicitar que el funcionario declare en audiencia, a fin de complementar alguna información sobre un caso. De manera que pareciera haber, más bien, una concepción de trabajo "en equipo" con los propios compañeros, dentro del cual se pueden apreciar rituales de jerarquía y entrenamiento, aún al margen de la legalidad; al respecto son interesantes los comentarios siguientes:

No creo que haya castigo sin apoyo [...] hace muy poco apareció por televisión un grupo de policías pateando a una persona, eran varios funcionarios. Eso ocurre con mucha frecuencia. Los maltratos verbales y físicos se distribuyen de acuerdo con el rango de los funcionarios. El primero que maltrata es el jefe de la comisión [...] se va arrinconando hasta llevarlo a un lugar donde haya poca luz, poca gente o nadie más que los policías, se golpea y luego se esposa. (Entrevista 5)

... en las policías hay trabajo en equipo. Yo tengo un grupo de compañeros con los que formamos un grupo para castigar y tenemos códigos secretos. El castigo es en equipo. A mayor presencia policial en una situación, uno lo va evaluando. Hay códigos secretos entre los funcionarios, si pasa $\mathrm{X}$, ocurre $\mathrm{Y}$ así tienes mejor disponibilidad de tiempo y más efectividad en el trabajo. No necesitamos protección de más nadie, con nosotros nos bastamos. (Entrevista 13)

Estas apreciaciones de trabajo policial son interesantes en cuanto al apoyo del equipo de trabajo, aunque el castigo policial parece hacer referencia a prácticas clandestinas o con escasa visibilidad. Si esto es así, hay un poder autónomo de la policía para castigar. De este modo, se pasaría de una policía preventiva a una policía que pretende aplicar castigo directo, antes que reportar el caso ante el fiscal; y con ello habría un doble proceso: cuando el funcionario tiene el encuentro con el ciudadano, en el cual se evalúa la decisión de castigar, con anterioridad al levantamiento del acta policial, y luego, cuando ésta es remitida al fiscal.

El anclaje normativo mayormente mencionado sobre los procedimientos de castigo fue la Ordenanza de Convivencia Ciudadana y Sanciones de Infracciones Menores (Venezuela, 2001), cuyo texto prevé la competencia de las policías del Distrito Metropolitano para resolver sobre sanciones a fin de preservar la convivencia ciudadana, el orden público, el ambiente, el ornato, el buen estado de los bienes públicos y la libre circulación, tránsito y utilización pacífica y armónica de las vías y los espacios públicos del área Metropolitana de Caracas.

Las normas de la Ordenanza describen faltas menores o incivilidades y su sanción pecuniaria hasta 20 unidades tributarias o 48 horas de trabajos comunitarios. Según el art. 2, literal: e) los funcionarios policiales del área metropolitana de Caracas son competentes "para hacer cumplir la presente ordenanza y aplicar las sanciones previstas en ella” y, según el art. 45, cuando se trata de flagrancia puede el infractor ser trasladado "a la dependencia del organismo de adscripción”, donde se levanta un acta haciendo constar las circunstancias de tiempo, lugar y características personales. Aunque el art. 36 establece el derecho de asistencia por abogado, lo sumario del procedimiento hace dudosa la efectividad de tal asistencia. Por otro lado, dado que la designación de las autoridades que deban conocer el procedimiento se encomienda a los alcaldes de los diversos municipios, no hay, en la Ordenanza, una disposición que establezca para los funcionarios uniformados de servicio una potestad de castigo en sentido estricto, aún para este rango de faltas menores que incluye, entre otras, ingesta alcohólica en lugares públicos, disposición de excretas, deterioro de muros, bloqueo de vías, ruidos molestos y ofrecimiento de servicios sexuales. Sin embargo, la referencia a esta Ordenanza puede explicar la tendencia de los entrevistados a referirse al castigo de faltas, antes que delitos, si bien en muchos comentarios se evidencia que los supuestos de estas mismas faltas no están claros y que se utilizan normas procesales como respaldo para facultades de sanción que no existen desde el punto de vista legal:

... las meretrices están preparadas para rasguñar con las hojillas que se colocan debajo de la lengua. Yo no creo que esté prohibido ser prostituta; es por mantener el orden de la zona que uno les 
puede pedir que se retiren. La única forma que sean detenidas es que se pongan agresivas con la comisión. Esa detención para ellas es un castigo. Yo en particular no les pego, pero ellas afean el lugar. ¿Qué va a pensar la gente cuando camina por el boulevard?[...] Pero el castigo también son multas, si te tragaste la luz del semáforo, la multa son 10 unidades tributarias. Cada una sale en 14.900 Bolívares., son casi 150.000 Bolívares. Si es certificado médico vencido, son 56.000 bolívares. Andar sin casco son 40.000,00 Bolívares [...] yo no se si la prostitución se multa o no, [...] yo me apego a la Ordenanza, pero no la he leído. Me imagino que la gente tampoco, aunque la venden los buhoneros de la Plaza Caracas. Si la acción no está establecida en la norma, ley u ordenanza, no se aplica el castigo. Tú te apegas al COPP, eso es lo más importante para no buscar problemas. Tienes que hacer mención de los derechos del imputado que dice el COPP. Lo que dice la ley uno lo hace. (Entrevista 11)

Los funcionarios policiales, a su vez, hacen notar que no tienen claridad en cuanto a una guía que oriente el castigo. Algunos comentarios se pueden citar al respecto:

...eso depende de la situación, te podemos quitar la mercancía o llevar presos... (Entrevista 5)

... a veces el fiscal da luz verde para que nosotros apliquemos el castigo menor, pero sin testigos. (Entrevista 11)

No es muy claro, pero a veces se puede distinguir con mayor facilidad entre faltas y delitos, otras veces no. (Entrevista 10)

La flexibilidad del juicio sobre la oportunidad y modalidad del castigo a imponerse puede ser muy grande cuando la incertidumbre o ambigüedad rodean la situación que amerita la intervención, como ilustra bien el presente caso de violencia doméstica:

... yo los golpeé a los dos. El hombre estaba pegándole a la mujer en vía pública, yo lo agarré y le di, le metí una llave. Como el hombre faltó el respeto a la autoridad porque no se dejaba revisar, le di, le di y le di por las nalgas.

Cuando la mujer golpeó al funcionario, se produjo una reacción policial de castigo hacia ella, manifiesta en la brusquedad del trato:

A ella la tiré al lado del hombre, al hombre le dije, mátala si quieres. Yo no me meto en esos casos más nunca. (Entrevista 8).
La modalidad policial para castigar varía según las contingencias, y las decisiones adoptadas parecen responder a una evaluación situacional no reglamentada, sino construida con máximas de experiencia.

... cuando uno está en la práctica es otra cosa, otra cosa es cuando uno esta estudiando que a uno le decían todo el tiempo [...] no puedes golpear a nadie, pero que va la situación en la calle te empuja y la teoría no es aplicable al 100\%. (Entrevista 1)

El encuentro con el público en la calle es el escenario dentro del cual se aplica el castigo, dado que el trabajo administrativo es posterior. La operatividad en la calle permite al funcionario desarrollar la competencia para adecuar el comportamiento policial al momento determinado. Esta situación puede generar incertidumbre en cuanto al tipo de castigo aplicado por parte de los policías y sobre las expectativas del público. Algunos autores consideran que esta es una propiedad estructural de la organización policial, por cuanto, en la policía, no habría manera de definir reglas sobre las respuesta policiales, dado que la jerarquía permite la discreción a sus funcionarios y los superiores sirven solamente como asesores de los funcionarios (Manning, 1997, p.144-145; Skolnick, 1975, p.87). Esta tensión en cuanto a la aplicación del castigo se añade a la discordancia legalista, por cuanto si la policía es una instancia de control social formal, se espera de ella la aplicación de mecanismos ya previstos en las normas relacionadas con el procedimiento policial autorizado para el control de una situación determinada.

\section{Dimensión moral y justificación del castigo}

La segunda proposición en esta investigación está relacionada con el juicio moral que hacen los policías al tratar de aplicar el castigo. Este aspecto guarda relación con la frecuencia de interacción entre el policía y el ciudadano en la calle. 
Para resolver sobre el castigo policial, los funcionarios elaboran juicios sobre: victimario, situación y víctima. En el caso del victimario, la evaluación se centra en los antecedentes de los encuentros con la policía y, si se trata de la víctima, la evaluación toma en cuenta la respetabilidad de la persona en quien recayó el daño del delito o la falta. Como se ha sostenido, la censura moral respecto a un evento y frente a un infractor se incrementa cuanto mayor es el daño del acto y mayor la respetabilidad de la víctima (Birkbeck; Gabaldón, 2001, p.100).

El moralismo (y por consiguiente, la devaluación moral) han sido vinculados a la distancia social. Black ha sostenido recientemente que el moralismo es una función directa de la lejanía y la superioridad sociales, que la proximidad social desestimula la aplicación de la distinción entre bien y mal y que el moralismo estimula la aplicación de la fuerza (2004, p.197, 200, 202). Si ello es así, podríamos admitir que la distancia social entre funcionarios policiales y sujetos infractores, definidos como moralmente devaluados, fomenta la aplicación de castigos. La desigualdad social, en la medida en que hace más duro el moralismo, incrementaría la probabilidad del castigo. Si consideramos que la frecuencia de los encuentros entre policía y victimario genera cierta continuidad, se puede decir que hay personas frente a las cuales el castigo policial se hace recurrente. Se podría sostener que se convierten en "clientes del castigo policial". Este "cliente" es una persona que recurrentemente ha evadido el control formal. Si esto fuera así, ante la constatación de tal evasión, puede haber una tendencia de aplicar modalidades del castigo extralegal.

Es posible, además, que la frecuencia de contactos con infractores facilite a la policía el conocimiento sobre sus antecedentes y condiciones de vida que, en caso de ser evaluados negativamente, sirvan de base para un juicio de condena moral. En estos casos, la reiteración del contacto podría determinar una mayor disposición a castigar en función de un juicio moral negativo. Algunos comentarios sobre contactos policiales con personas vinculadas al mercado informal sugieren el establecimiento policial de identidades moralmente devaluadas que facilitan la aplicación de castigos informales, aunque no sean muy intensos. Los siguientes comentarios son ilustrativos:

Por robo de una cadena a una señora, yo le dí una paliza, a la señora le devolví la cadena. Ella estaba sorprendida que logró recuperarla, con los tribunales no lo habría logrado. Al sujeto le dí un toque técnico. Ese es un hampón, aparece solicitado por otras razones. Ir a la fiscalía es un problema, uno lo que hace es perder tiempo. Mira yo recuerdo que le dí, el tipo se quiso levantar del suelo y le dí. Me lo llevé pa un lugar no me preguntes el nombre [...] yo sé dar duro sin que se noten los moretones. Si tuviéramos proceso, yo no lo golpeo, pero como no lo tenemos, yo lo hago. A ese tipo le di palo toda la tarde, hasta que dijera que se iba a portar mejor. Ese es un buhonero, de los de ahí abajo. Esos, todos los buhoneros son unos balandros, el buhonero te vende droga y en su mayoría tienen antecedentes. Nosotros los conocemos a todos. (Entrevista 14).

\section{Otro funcionario comentó:}

En el caso de los cidiceros [vendedores de copias ilegales de discos compactos] [...] en esa situación si se presenta desacato, el castigo muere en el decomiso de la mercancía, ellos, la pierden y tienen que dejarlo aquí, porque, como es sabido, las copias son ilegales y las tienen que dejar aquí. Yo le castigo como lo establece la Ordenanza, si no busca alguien que te defienda. Ellos saben que nadie los puede defender porque venden mercancía ilegal, espero que esto te sirva de escarmiento. (Entrevista 8).

Se podría sostener que las personas moralmente devaluadas tienen menos poder de reclamo por cuanto, al estar comprometida la respetabilidad personal, la credibilidad de un reclamo se hace menos probable. Esto ayuda a explicar la mayor facilidad para aplicar castigos a personas moralmente devaluadas, incluyendo el uso directo de la fuerza física. Sin embargo hay que tomar en cuenta que el poder de reclamo podría ser independiente de la dimensión moral, cuando, debido a la posición social o política, se tienen posibilidades de evadir los castigos. En estos casos, pese a existir una inclinación para castigar, se puede llegar a la abstención de hacerlo por temor a las consecuencias negativas que, para el funcionario policial, podría acarrear un reclamo por parte de la víctima 
del castigo. La vinculación entre el uso de la fuerza, el poder de reclamo y la debilidad de los procedimientos para exigir rendición de cuentas ha sido estudiada en el caso venezolano a nivel de las actitudes y reglamentos policiales (Gabaldón; Birkbeck, 1996; 1998; Birkbeck; Gabaldón, 2002; Birkbeck; Gabaldón; Norris, 2003) y ha sido establecida para la ocurrencia efectiva de la fuerza física aplicada por la policía a jóvenes marginados, tanto en Venezuela como en Brasil (Gabaldón; Serrano, 2001, p.63; Huggins; Mesquita, (1995, p.266). En las entrevistas desarrolladas en la presente investigación, la asociación entre castigo y poder de reclamo se manifiesta como inhibición de la aplicación de castigos por parte de la policía, independientemente del juicio sobre la dimensión moral del hecho o del protagonista. Los siguientes relatos así lo confirman:

Mira, si es un azote de barrio, es un delincuente, lo puedo castigar, pero no puedo detener a alguien que tenga billete. (Entrevista 8).

... yo estaba cumpliendo funciones de tránsito. Se trataba de dos canales de circulación, pero uno estaba siendo obstruido por un vehículo, el conductor resultó ser capitán de Ejército. Le pedí papeles e identificación, y el ciudadano me dijo "tu no ves lo que yo cargo aquí [el entrevistado sacude la solapa del uniforme, simulando las insignias que le mostró el militar]. (Entrevista 4)

Comenta el entrevistado que se desplazó

del lugar y de haber sido otra persona lo habría multado, para castigar.

Un entrevistado comentó que, en alguna oportunidad, ciudadanos han roto las boletas impuestas y alegan "tu no sabes quién soy yo" (Entrevista 12). El funcionario simplemente dice que, ante esos casos, prefiere retirarse del lugar, o llevarlos al comando.

De acuerdo con estos comentarios, las personas con poder de reclamo no deben ser consideradas como sujetos pasivos del castigo policial. Es posible que el área metropolitana de Caracas refleje una estratificación social, que implique mayor vulnerabilidad de unos ciudadanos frente a otros, frente a los dos cuerpos policiales a que se refiere la presente investigación.
En este sentido, la estratificación social reflejaría distintas posibilidades para la conformación de una "clientela" para el castigo, sobre la base de contactos reiterados, devaluación moral y escaso poder de reclamo social. Sin embargo, la constatación de esta conjetura demanda datos que rebasan los límites del presente trabajo.

\section{CONCLUSIONES Y PERSPECTIVAS}

La actividad de castigar, de acuerdo con la literatura legalista, no está reservada para la policía; sin embargo, los resultados en esta investigación indican que los funcionarios policiales asumen entre sus funciones castigar a los ciudadanos.

La opinión de los entrevistados no reveló un criterio uniforme sobre lo que es castigo, no registró uniformidad en cuanto a la tipificación normativa de delitos y faltas, ni asumió claridad en cuanto a las modalidades y los mecanismos para graduar la intensidad del castigo. Lo que sí resultó claro es que el castigo es un procedimiento que formal o informalmente se activa frente a una conducta negativa.

El castigo policial es informal y responde a criterios respaldados por los mismos compañeros de trabajo. Esta es posiblemente una relación de "equipo", con apoyo grupal, más que con fiscalía y tribunales, instancias con las cuales el vínculo posiblemente representa la necesidad de protección cuando se enfrenta un reclamo formal ante un exceso.

El castigo policial, de acuerdo con los resultados de esta investigación, supone prácticas de mayor o menor visibilidad, pero en ningún caso se refieren claramente a normas formales. Si bien la Ordenanza de Convivencia Ciudadana suele citarse como base para intervenir ante las faltas, los funcionarios no parecen tener muy claro cuáles son las faltas que se encuentran tipificadas y sus correspondientes formas de sanción. No pareciera evidenciarse un procedimiento claro para castigar, lo cual no es sorprendente si se considera que la 
decisión de castigar representa un juicio personalizado sobre el terreno y ante cada situación.

La aplicación de castigo tiene como referente una dimensión moral vinculada a la clientela del castigo. Esto significa que, en la medida en que el victimario ha tenido contactos anteriores con la policía con ocasión de faltas o delitos cometidos, habiendo fallas para sancionar por parte del control formal, el agente policial se muestra severo al aplicar castigo. De acuerdo con este trabajo, algunas actividades laborales, como el comercio informal, parecieran estar asociadas con los sujetos pasivos del castigo policial. Aunque no hay relación directa entre devaluación moral y bajo poder de reclamo, de acuerdo con los resultados reportados en este trabajo, parece que, si el victimario resulta alguien con capacidad de denunciar y sostener un proceso en contra de un policía por un castigo "ilegal", se minimiza la posibilidad de castigo policial. El juicio moral del funcionario parece tomar en consideración, tanto características de la conducta como del ciudadano al cual se aplica el castigo.

El estudio en materia de castigo debería complementarse con el tipo de fuerza que se emplea para castigar. Ello permitiría establecer una conexión entre la magnitud de la censura y la intensidad del castigo. De igual modo, debe analizarse mejor la percepción de ineficacia del aparato formal de justicia para enfrentar los casos que implican fuerte censura moral, y, en este sentido, determinar si la aplicación de castigo por parte de la policía obedece a la siguiente secuencia: el comportamiento o el sujeto son objetos de censura moral, y, por consiguiente, merecen castigo; dado que la justicia formal no es efectiva, corresponde aplicarlo directamente a la policía, como un mecanismo supletorio. La investigación sobre esta relación permitirá comprender mejor los mecanismos de vinculación entre el control social formal e informal dentro del sistema de justicia penal.

(Recebido em agosto 2010) (Aceito em outubro 2010)

\section{REFERÊNCIAS}

BLACK,D. Social control as dependent variable. En: BLACK, D. (Org..) Toward a general theory of social control. Fundamentals. Orlando: Academic Press, v.1, 1984. p.1-36. BIRKBECK, Christopher; GABALDÓN, Luis Gerardo. La definición de los usos justificados de la fuerza en el desempeño policial: propuesta para un proyecto de investigación comparada. In: GABALDÓN, Luis G.; BIRKBECK,Christopher (Orgs.) Policía y fuerza física en perspectiva intercultural. Nueva Sociedad, Caracas, p.125137, 2003.

; GABALDÓN, Luis Gerardo. Offender morality and the criminal event. In: MEIER, Robert; KENNEDY, Leslie W.; SACCO, Vincent F. (Orgs.) The process and structure of crime. New Brunswick: Transaction, 2001. p.95-124.

. Exigiendo responsabilidad en la policía venezolana. Nueva Sociedad, Caracas, n.182, nov./dic., p.4758,2002 .

; NORRIS, Michael. La disposición de usar la fuerza contra el ciudadano: un estudio de la policía en cuatro ciudades de las Américas. Capítulo criminológico, Lima, v.31, n.2, abr./jun., p.33-77, 2003.

BLACK, Donald. La estructura social del bien y el mal: enemistándose. Revista Cenipec, Mérida,Ve, v.23, p.195-221, 2004.

BRICEÑO LEÓN, Roberto. ¿Tiene la policía derecho a matar delincuentes? Un estudio del apoyo ciudadano a la violencia policial. In: ___ PÉREZ PERDOMO, Rogelio (Orgs.) Morir en Caracas. Caracas: Universidad Central de Venezuela. 2002. p.180-192.

CANO, Ignacio. Policía, paramilitares y escuadrones de la muerte en América Latina.In: BODEMER, Klaus; KURTENBACH, Sabine; MESCHKAT, Klaus (Orgs.) Violencia y regulación de conflictos en América Latina. Nueva Sociedad, Caracas. p.219-325, 2001.

DEL OLMO, Rosa. El castigo sin derecho a castigar: la violencia policial y la violencia carcelaria. In: _. Segunda ruptura criminológica. Caracas. Universidad Central de Venezuela, 1990. p.37-67.

GABALDÓN, Luis Gerardo. Control social y criminología. Caracas. Editorial Jurídica Venezolana, s.d.

; BIRKBECK, Christopher. Estatus social, comportamiento ciudadano y violencia policial: una evaluación actitudinal en policías venezolanos. Capítulo Criminológico, Lima, v.24, n.2, jul./dic., p.31-59. 1987.

. Criterios situacionales de funcionarios policiales sobre el uso de la fuerza física. Capítulo Criminológico, Lima, v.26, n.2, jul./dic., p.99-132, 1996. ; BETTIOL, Daniela. La policía en el vecindario. Mérida: Universidad de Los Andes; Gobernación del Estado, 1990.

; SERRANO, Carla Violencia urbana: perspectivas de jóvenes transgresores y funcionarios policiales en Venezuela (em colaboração com Yoana Monsalve e Cristian Sanginés). Caracas: Universidad Católica Andrés Bello, 2001. GARLAND, David. Castigo y sociedad moderna. México: Siglo XXI, 1999.

GRABOSKY, Peter. The variability of punishment. In: BLACK, Donald (Org.) Toward a general theory of social control. Orlando: Academic Press, 1984. v.1 p.163-183.

HUGGINS, Martha; HARITOS-FATOUROS, Mika. Conciencia torturada: secretos y moralidad en la violencia policial brasileña. In: WALDMANN, Peter (Org.). Justicia en la calle. Ensayos sobre la policía en América Latina. Medellín: Diké, 1996. p.323-354. 
; MESQUITA Myriam P. Scapeogoating outsiders: the murders of street youth in modern Brazil. Policing and Society, n.5, p.265-280, 1995.

LYMAN, Stanford M.; SCOTT, Marvin B. A sociology of the absurd. New York: General Hall, 1989.

MANNING, Peter Police work. The social organization of policing. [S.l.]: Prospect Heights; Waveland Press, 1997.

. Policing contingences. Chicago: University of ChiCago Press, 2003.

MÁRQUEZ, Patricia; CASTILLO, Anabel. ¿Nuevas soluciones a viejos problemas?: las policías municipales del área metropolitana de Caracas. In: BRICEÑO LEÓN, Roberto PÉREZ PERDOMO, Rogelio (Orgs.) Morir en Caracas. Caracas: Universidad Central de Venezuela, 2002. p.147-177.

PROVEA -Programa Venezolano de Educación- Accción en Derechos. Situación de los derechos humanos en Venezuela. Informe Anual, oct., 2002 -sep. 2003. Caracas: Provea, 2003.
STANLEY, Ruth. Violencia policial en el Gran Buenos Aires: ¿ Necesita neoliberalismo una policía brava?. In: BODEMER Klaus; KURTENBACH, Sabine; MESCHKAT, Klaus (Orgs.) Violencia y regulación de conflictos en América Latina. Nueva Sociedad, Caracas, v.1, p.237-256, 2001.

VENEZUELA (VE). Ordenanza de convivencia ciudadana y sanciones de infracciones menores. Gaceta Oficial,Caracas, n.37.180, fecha 18 de abril de 2001.

WALKER, Samuel. The police in America an introduction. New York: Mc Graw Hill. 1992.

ZAFFARONI, Eugenio Raúl. En busca de las penas perdidas. Buenos Aires: Ediciones Ediar, 1989. 
SOCIAL CONTROL AND PUNISHMENT: perception of punishment to Venezuelan police officers

\section{Yoana Monsalve Briceño}

The paper addresses issues of the meaning of punishment for the police and the moral justifications for its application, using data from 14 interviews with officials from two police forces in the area of Caracas, Venezuela. Although, at first glance, the exercise of the power to punish is perceived by the police as the jurisdiction of criminal judges, a more detailed reading indicates that they perceive, among the general public, a demand to act as direct executors of punishment. Thus, forms of organization and justification of illegal punishment appear, with these officers accepting a delegation or implied consent by other operators in the justice system. There is also the emergence of a "clientele" of punishment, formed by morally devalued people with little power of social demand, although both dimensions keep certain autonomy. It concludes with proposals to enlarge the scope of research and to analyze the extent and consistency of perceptions of inefficiency of the formal criminal justice system and its influence on the development of the power of direct punishment by the police.

KEYWORDS: punishment, police, criminal justice, informal control, morality, Venezuela.
CONTRÔLE SOCIAL ET PUNITION: perception de la punition par des policiers vénézuéliens

\section{Yoana Monsalve Briceño}

L'article aborde les questions concernant le sens de la punition d'un point de vue policier et les justifications morales de son application. L’analyse est faite à partir des données provenant de 14 interviews réalisées auprès de fonctionnaires des deux forces de police de la région de Caracas au Venezuela. Même si, à première vue, l'exercice du pouvoir d'application des punitions est perçu par la police comme relevant de la juridiction pénale des juges, une analyse plus détaillée montre que la police perçoit que les citoyens attendent d'elle qu'elle assume un rôle d'application directe des peines. C'est ainsi que des formes d'organisation et de justification de peines illégales surgissent, qui font que les policiers assument d'être les délégués ou reçoivent le consentement implicite d'autres représentants de la justice. On voit aussi surgir une 'clientèle' de la punition, formée par des personnes dévalorisées moralement et ne jouissant que d'un pouvoir limité de revendications sociales, même si ces deux dimensions gardent une certaine autonomie. L'article termine sur des propositions visant à élargir le champ de recherche et à analyser l'étendue et la consistance des perceptions de l'inefficacité du système formel de justice pénale et son influence sur le développement du pouvoir de punition directe de la police.

Mots-CLÉs: punition/châtiment, police, justice pénale, contrôle informel, moralité, Venezuela.

Yoana Monsalve Briceño - Advogada. Mestre em Planejamento do Desenvolvimento, Política Social pela Universidade Central de Venezuela. Professora do Departamento de Controle Social, Universidade de Los Andes, Escola de Criminologia. Coordenador(a) do Programa Necessidades sociais e projetos privados, Universidade Los Andes. Integra o Grupo de Investigações Criminológicas, desenvolvendo pesquisas sobre Polícia, Segurança Pública; necessidades e políticas sociais. Suas mais recentes publicações são: $L a$ calidad de vida y su relación con el servicio policial. Capítulo Criminológico, v. 37, nº 2, 2009; e Seguridad ciudadana, desempeño policial y la calidad de vida en las políticas sociales. Revista Venezolana de Economía y Ciencias Sociales, abr. 2009, v.15. 